\title{
Finite element analysis on influence of implant surface treatments, connection and bone types 方
}

\author{
Joel Ferreira Santiago Junior ${ }^{\text {a,* }}$, Fellippo Ramos Verri ${ }^{\text {b }}$, Daniel Augusto de Faria Almeida ${ }^{\text {b }}$, \\ Victor Eduardo de Souza Batista ${ }^{\mathrm{b}}$, Cleidiel Aparecido Araujo Lemos ${ }^{\mathrm{b}}$, Eduardo Piza Pellizzer ${ }^{\mathrm{b}}$ \\ a Department of Health Sciences, University of Sacred Heart, USC, 10-50 Irmã Arminda, Jardim Brasil, Bauru 17011-160, SP, Brazil \\ b Department of Dental Materials and Prosthodontics, Araçatuba Dental School, 1193 José Bonifácio Street, Vila Mendonça, Araçatuba 16015-050, UNESP-Univ Estadual Paulista, Brazil
}

\section{A R T I C L E I N F O}

\section{Article history:}

Received 3 November 2015

Received in revised form 2 February 2016

Accepted 19 February 2016

Available online 22 February 2016

\section{Keywords:}

Dental implant design

Surface treatments

Finite element analysis

\begin{abstract}
A B S T R A C T
The aim of this study is to assess the effect of different dental implant designs, bone type, loading, and surface treatment on the stress distribution around the implant by using the 3D finite-element method. Twelve 3D models were developed with Invesalius 3.0, Rhinoceros 4.0, and Solidworks 2010 software. The analysis was processed using the FEMAP 10.2 and NeiNastran 10.0 software. The applied oblique forces were $200 \mathrm{~N}$ and $100 \mathrm{~N}$. The results were analyzed using maps of maximum principal stress and bone microstrain. Statistical analysis was performed using ANOVA and Tukey's test. The results showed that the Morse taper design was most efficient in terms of its distribution of stresses $(p<0.05)$; the external hexagon with platform switching did not show a significant difference from an external hexagon with a standard platform $(\mathrm{p}>0.05)$. The different bone types did not show a significant difference in the stress/strain distribution $(p>0.05)$. The surface treatment increased areas of stress concentration under axial loading $(\mathrm{p}<0.05)$ and increased areas of microstrain under axial and oblique loading $(\mathrm{p}<0.05)$ on the cortical bone. The Morse taper design behaved better biomechanically in relation to the bone tissue. The treated surface increased areas of stress and strain on the cortical bone tissue.
\end{abstract}

(c) 2016 Elsevier B.V. All rights reserved.

\section{Introduction}

Dental implants have improved the quality of life for millions of patients in recent decades; further, they have shown high successful predictability [1]. However, one of the main challenges has been to indicate which dental implant design shows the best biomechanical behavior for each existing clinical situation $[2,3]$.

The literature indicates that different biomechanical factors can influence the stress distribution around an implant $[2,4,5]$. Biomechanically, the effectiveness of a dental implant design is dependent on the way that the stresses are transmitted to the bone tissue [6].

In this context, there is no consensus about the best option for dental implant design, since external hexagon implants show reversibility that is suitable for implant-supported prostheses [3]. Furthermore, longitudinal studies over the course of several years have indicated high survival rates of dental implants [1,7]; however, the external hexagon implants have been associated with rates of bone loss that exceeds $1.5 \mathrm{~mm}$ over the years [8], compared to Morse taper and platformswitching implants $[7,9,10]$.

\footnotetext{
is These authors contributed equally to the manuscript.

* Corresponding author at: Department of Health Sciences, University of Sacred Heart, USC, 10-50 Irmã Arminda, Jardim Brasil, Bauru 17011-160, SP, Brazil.

E-mail address: jf.santiagojunior@gmail.com (J.F. Santiago).
}

In this respect, the dental implant platform-switching concept (PSW), in which a narrow diameter abutment is placed on an external hexagon implant of a wider diameter, has been associated with lower marginal bone loss [9,11]. Nevertheless, more biomechanical studies are necessary in order to assess this concept in the clinical situation of low-density bone.

Another relevant biomechanical factor is related to the quality of bone type that is available for rehabilitation with dental implants [1, 12-14]. Some studies have indicated that type IV bone is more susceptible to biomechanical damage than other bone types (I-III) $[5,12$, 14-16]. Clinically, some studies have reported a higher rate of failure of implants placed in low-density bone [1,17]. However, no study has evaluated the best biomechanical profile of each dental implant design for low-density bone.

Finally, the surface treatments of implants have been indicated as a pertinent factor for the longevity of this modality of treatment [1]. Moreover, the surface treatment in implants placed in low-density bone (type IV) has been associated with a high survival rate of dental implants $[1,18]$. However, there are few studies that have evaluated the biomechanical behavior of surface-treated versus machined surface implants $[19,20]$.

In this context, biomechanical studies offer substantial information, since they may indicate a parameter for situations involving lowdensity bone (types III and IV) in conjunction with different dental implant designs and surface treatments. Thus, the aim of this study is to 
assess the effect of different dental implant designs (i.e., an external hexagon with a standard platform, an external hexagon with platform switching, and Morse taper), bone types (III and IV), loading (axial and oblique), and surface treatment (treated and machined) on the stress distribution around an implant by using the 3D finite-element method. The study hypotheses are as follows: 1 ) dental implants ( $\varnothing$ $5 \mathrm{~mm}$ ) with a platform-switching concept show stress distribution on the cortical bone around an implant that is similar to external hexagon implants ( bution on the cortical bone around an implant. 3) Dental implants placed in type IV bone show the largest area of stress concentration in comparison to dental implants placed in type III bone. 4) Surfacetreated dental implants show the best stress distribution on cortical bone compared to machined surface implants.

\section{Material and methods}

\subsection{Experimental design}

This research was developed by considering four factors of study: the dental implant design (an external hexagon with a standard platform or an external hexagon with platform switching and a Morse taper), bone types (III and IV), surface treatment (treated and machined), and loading (axial and oblique).

\subsection{Three-dimensional design and FE analysis scenarios}

This methodology follows previous studies [2,4,21]. Twelve 3D models were developed (Table 1 ), thus representing a section of mandibular bone of the second molar region with an implant and singleunit crown.

The geometry of the bone tissue, a region of mandibular bone with a dental implant and implant-supported crown, was obtained by the decomposition of computed tomography through the use of InVesalius ${ }^{\circledR}$ software (CTI, Campinas, São Paulo, Brazil) and simplified in the Rhinoceros 4.0 software (Seattle, WA, USA), which was modeled via trabecular bone in the center, surrounded by a $1 \mathrm{~mm}$ layer of cortical bone. The implant design was obtained by simplifying two original dental implants within the Conexão® System (Conexão Sistemas de Prótese Ltda., Arujá, SP, Brazil), an external hexagon and Morse taper, with dimensions of $10 \times 5 \mathrm{~mm}$. All implants and abutments were simplified by

Table 1

Model description.

\begin{tabular}{|c|c|c|c|c|}
\hline Implant & Surface & Bone type & Design & Model \\
\hline \multirow[t]{12}{*}{$\begin{array}{l}\text { Implant } \\
\qquad(5 \times 10 \mathrm{~mm})\end{array}$} & Machined & III & External hexagon & $\begin{array}{l}\text { Model } 1 \\
(\mathrm{M})\end{array}$ \\
\hline & & & Platform switching & $\begin{array}{l}\text { Model } 2 \\
\text { (MM2) }\end{array}$ \\
\hline & & & Morse taper & $\begin{array}{l}\text { Model } 3 \\
(3 \mathrm{M})\end{array}$ \\
\hline & & IV & External hexagon & $\begin{array}{l}\text { Model } 4 \\
(\mathrm{M})\end{array}$ \\
\hline & & & Platform switching & $\begin{array}{l}\text { Model } 5 \\
(\mathrm{M})\end{array}$ \\
\hline & & & Morse taper & $\begin{array}{l}\text { Model } 6 \\
(\mathrm{M})\end{array}$ \\
\hline & Treated & III & External hexagon & $\begin{array}{l}\text { Model } 7 \\
\text { (M) }\end{array}$ \\
\hline & & & Platform switching & $\begin{array}{l}\text { Model } 8 \\
(\mathrm{M})\end{array}$ \\
\hline & & & Morse taper & $\begin{array}{l}\text { Model } 9 \\
(\mathrm{M})\end{array}$ \\
\hline & & IV & External hexagon & $\begin{array}{l}\text { Model } 10 \\
(\mathrm{ML})\end{array}$ \\
\hline & & & Platform switching & $\begin{array}{l}\text { Model } 11 \\
(\mathrm{M} 11)\end{array}$ \\
\hline & & & Morse taper & $\begin{array}{l}\text { Model } 12 \\
(\mathrm{M} 12)\end{array}$ \\
\hline
\end{tabular}

SolidWorks 2010 software (SolidWorks Corp, Concord, MA, USA) and Rhinoceros 4.1 (Seattle, WA, USA). The crown was modeled with a $10 \mathrm{~mm}$ height; it was screwed in the external hexagon and platformswitching models and cemented in the Morse taper model. The design of the crown surface was digitized from 1 artificial second mandibular molar (Odontofix Industria e Comercial de Material Odontologico Ltda., Ribeirão Preto, SP, Brazil). The occlusal lining material used was feldsphatic porcelain, and a nickel-chromium alloy was used for crown framework [4,22].

The implant surface modeling was performed by simulating bonded contact on all implant faces and bone tissue. The drawing of the implant and simplification was conducted using 2010 SolidWorks software (SolidWorks Corp., Waltham, MA, USA) [21]. The machined surface was considered a flat contact surface between the bone tissue and implant, according to previous studies $[2,4,21]$. The surface treatment was considered in 4 different regions of the implant (mesial, distal, buccal, and lingual). The development of a surface area increase of approximately $57 \%$ of the original area was considered on each of the faces that were analyzed. The surface-area increase was obtained through modeling the spherical surfaces in the region of the implant platform, consistent with the cortical bone, which was elaborated with 16 spherical (diameter: $95 \mu \mathrm{m}$; radius: $47.5 \mu \mathrm{m}$; surface area of 1 hemisphere in contact with bone tissue: $14,169 \mathrm{~m}^{2}$ ) in each implant surface, according to other studies that were previously conducted $[23,24]$.

After completion of the modeling, the finite-element software FEMAP 10.2 (Siemens PLM Software Inc., Santa Ana, CA, USA) was used to create finite-element models in the pre-processing stages. Thus, all meshes were generated by using tetrahedral parabolic solid elements.

All mechanical properties of each simulated material were attributed to the meshes by using literature values, according to Table 2 [16, 25-27] In order to analyze the type III bone and type IV bone, the modulus of elasticity of the type IV trabecular bone was modified [16]. All materials were considered isotropic, homogeneous, and linearly elastic.

Symmetric welds were simulated for all contacts, with the exception of the abutment/implant contact in the external hexagon and crown/ abutment, which was simulated by symmetric contact. The boundary conditions were fixed in all axes ( $\mathrm{x}, \mathrm{y}$, and $\mathrm{z}$ ) at both bone-block sections (anterior and posterior faces). All of the other model parts were under free restrictions. The applied force was $200 \mathrm{~N}$ axially (50 $\mathrm{N}$ at each cusp tip) and $100 \mathrm{~N}$ obliquely (50 $\mathrm{N}$ at each lingual cusp tip). Functional load was applied perpendicular to the chewing surfaces of the cusp [21].

Then, the finite element analysis was generated in the FEMAP 10.2 software and exported for mathematical calculation in the NeiNastran 11.0 software (Noran Engineering, Inc., Westminster, CA, USA), which was run on a workstation (HP Z200, Hewlett-Packard Company, Palo Alto, CA, USA) on which finite-element mesh for implants with a machined surface (Fig. 1a-c) and a treated surface (Fig. 1d-g) were generated. The results were imported again into the FEMAP 10.2 software for viewing and the post-processing of the maximum principal stress and microstrain maps. The levels of maximum principal stress and microstrain were analyzed in the cortical bone and measured in the mesial, distal, buccal, and lingual regions around each dental implant. The solid mesh convergence error showed the highest value for cortical bone in model 7 being less than 0.076 (7.1\%).

\subsection{Analysis of stress criteria}

The value of maximum principal stress was used as a criterion for stress analysis on bone tissue, since the use of this analysis is recommended for the compression and traction of friable materials. $[2,21$, 28]. The microstrain analysis ( $\mu$ Strain) [29] on bone tissue was used in order to allow a comparative analysis with maximum principal stress. The unit of measurement was the Megapascal (MPa) for maximum principal stress and $\mu$ Strain $(\mu \varepsilon)$ for the microstrain analysis of bone tissue. 
Table 2

Mechanical properties.

\begin{tabular}{lcll}
\hline & $\begin{array}{l}\text { Modulus of elasticity } \\
(E)(G P a: \text { gigapascals })\end{array}$ & $\begin{array}{l}\text { Poisson's } \\
\text { ratio }(\mu)\end{array}$ & References \\
\hline Type III bone & 1.3 & 0.30 & Sevimay et al. [16] \\
Type IV bone & 1.1 & 0.30 & Sevimay et al. [16] \\
Cortical bone & 13.7 & 0.30 & Sertgoz [25] \\
Titanium (implant) & 110.0 & 0.35 & Benzing et al. [26] \\
Nicer alloy & 206.0 & 0.33 & Anus vice [27] \\
Feldspathic porcelain & 82.8 & 0.35 & Sertgoz [25] \\
Zinc phosphate cement & 22.4 & 0.35 & Anusavice [27] \\
\hline
\end{tabular}

A detailed analysis of the structure of the cortical bone was performed for all models that were studied, including analysis of the maximum principal stress and bone microstrain. This cortical bone was selected because of its relevance to implantology, since this region accumulates the highest stress concentration in the bone tissue and provides an important biological function for the longevity of dental implants, as discussed in previous studies [2]; the microstrain analysis criterion was established in Frost's mechanostat theory $[2,21,28]$.

\subsection{Statistical analysis}

The effect of the type of loading (axial or oblique) was analyzed by three-way ANOVA regarding loading, models, and surface. The different types of bone tissue were analyzed by two-way ANOVA-models and bone type. The effect of different surface treatments was analyzed by three-way ANOVA-model, surface, and bone type-for each type of loading and surface simulated. All tests were performed by using values of maximum principal stress and bone microstrain. Values of $p<0.05$ were considered to be statistically significant. Tukey's post-hoc test was used to analyze interactions between results. Sigma Plot 12.3 (Systat Software Inc., San Jose, CA, USA) performed all statistical analyses.

\section{Results}

\subsection{Loading}

The loading analysis showed that oblique loading increased the area of stress concentration ( $p<0.001)$ and microstrain $(p<0.001)$ on the bone tissue compared to axial loading, as observed in Fig. 2a-b (maximum principal stress) and c-d (microstrain).

\subsection{Implant design}

The maximum principal stress showed that there were no significant differences in the stress distribution among the models under axial loading ( $p>0.05$; power of the test: $\alpha=0.871$ ) or oblique load (Figs. 2b and 3a); the Morse taper exhibited the lowest magnitude of stresses compared to the external hexagon with a standard platform $(\mathrm{p}<0.05)$ and the external hexagon with platform switching $(\mathrm{p}<0.05)$. The models with platform switching did not appear to be statistically significant in comparison to a standard platform $(\mathrm{p}>0.05)$.

The bone-microstrain analysis showed that the Morse taper exhibited the lowest magnitude of microstrain compared to an external hexagon with platform switching $(\mathrm{p}<0.05)$ and an external hexagon with a standard platform $(\mathrm{p}<0.001)$ for both loadings. The external hexagon with platform switching exhibited the lowest magnitude of microstrain compared to the external hexagon with a standard platform $(p<0.001)$, as shown in Fig. 3b. The highest magnitude values of microstrain and stress were observed under oblique loading.

\subsection{Bone types}

The maximum principal stress showed that there were no significant differences between the bone types (III and IV) and machined and treated surfaces in the magnitude of stress on the cortical bone $(p>0.05)$ under axial (Fig. 4a) and oblique loading (Fig. 4b).

The bone-microstrain analysis showed that, type IV bone increased the levels of bone microstrain, under an axial load and for an implant with a machined surface ( $p=0.047$ ), according to Fig. 4c. However, under oblique loading, there were no significant differences between the different bone types, regardless of the type of surface $(p>0.05)$, as shown in Fig. 4d.

\subsection{Surface treatment}

The maximum principal stress showed that type IV bone increased the levels of bone microstrain in the analyzed regions of the cortical bone under axial loading $(p<0.001)$ for all models. Under oblique loading, the surface treatment did not significantly modify $(p=0.139)$ the stress concentration around the implant. However, there was a decrease of the mean intensity of the stress concentration on bone tissue when compared to the implants with a machined (mean $=2.184 \mathrm{MPa}$ ) or

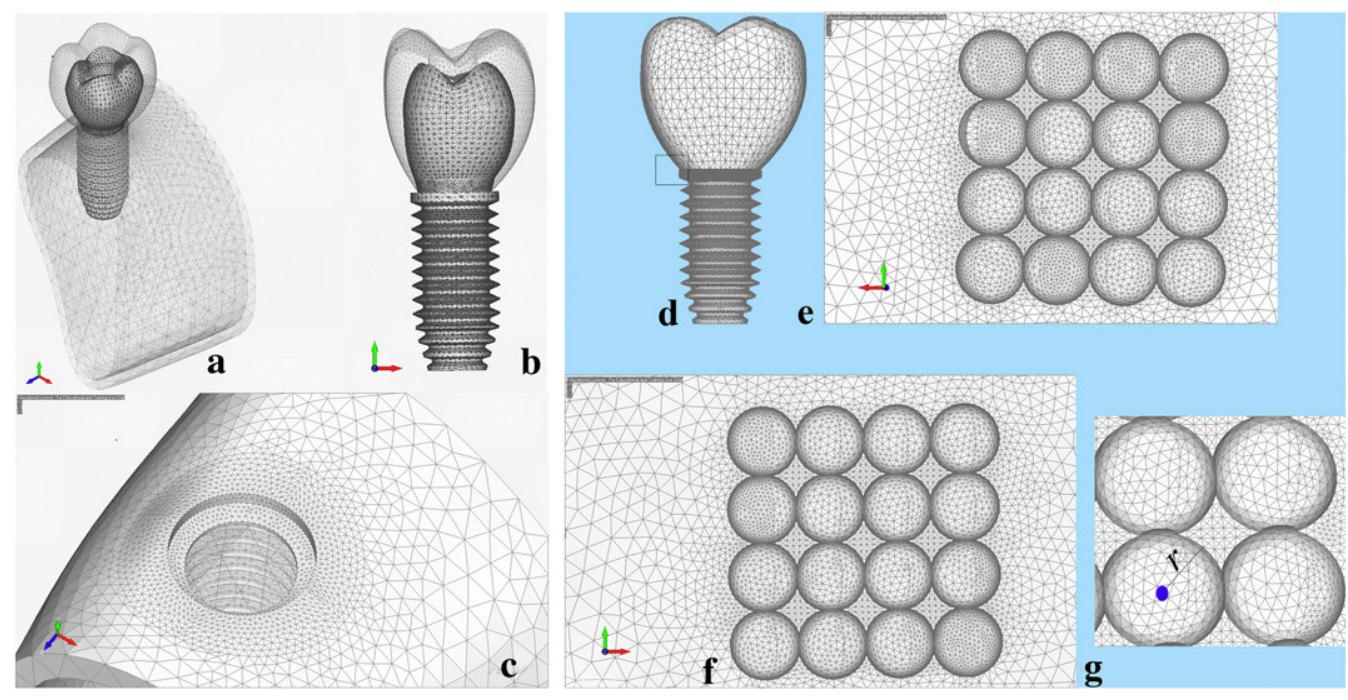

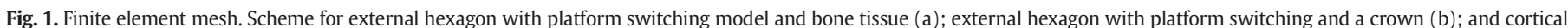

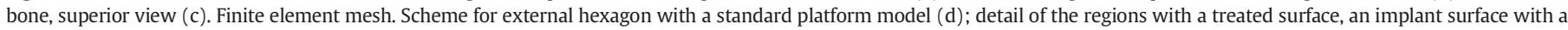

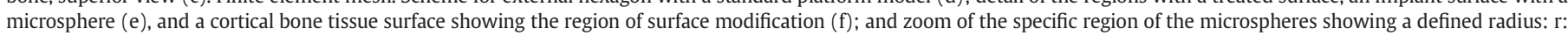
$47.5 \mu \mathrm{m}$ (g). 

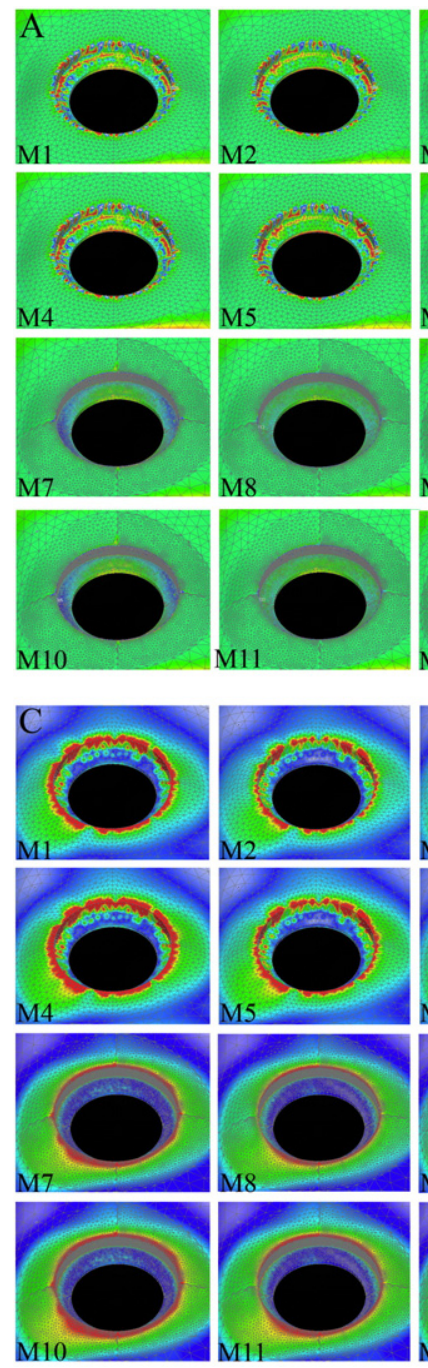
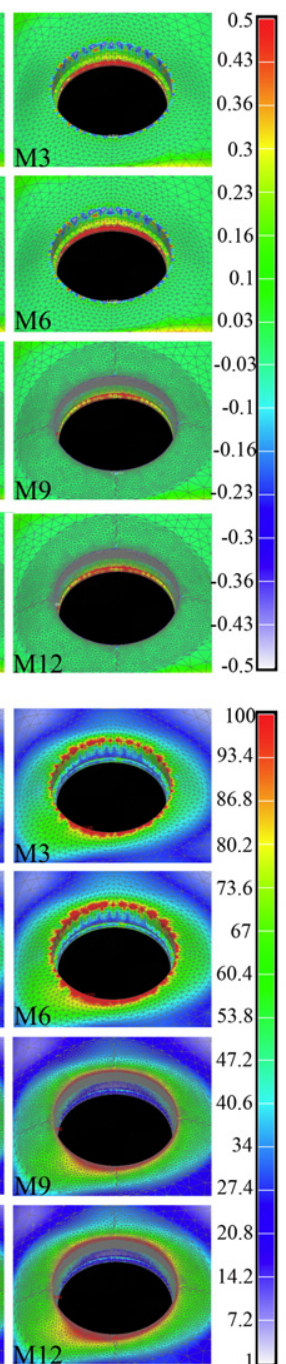
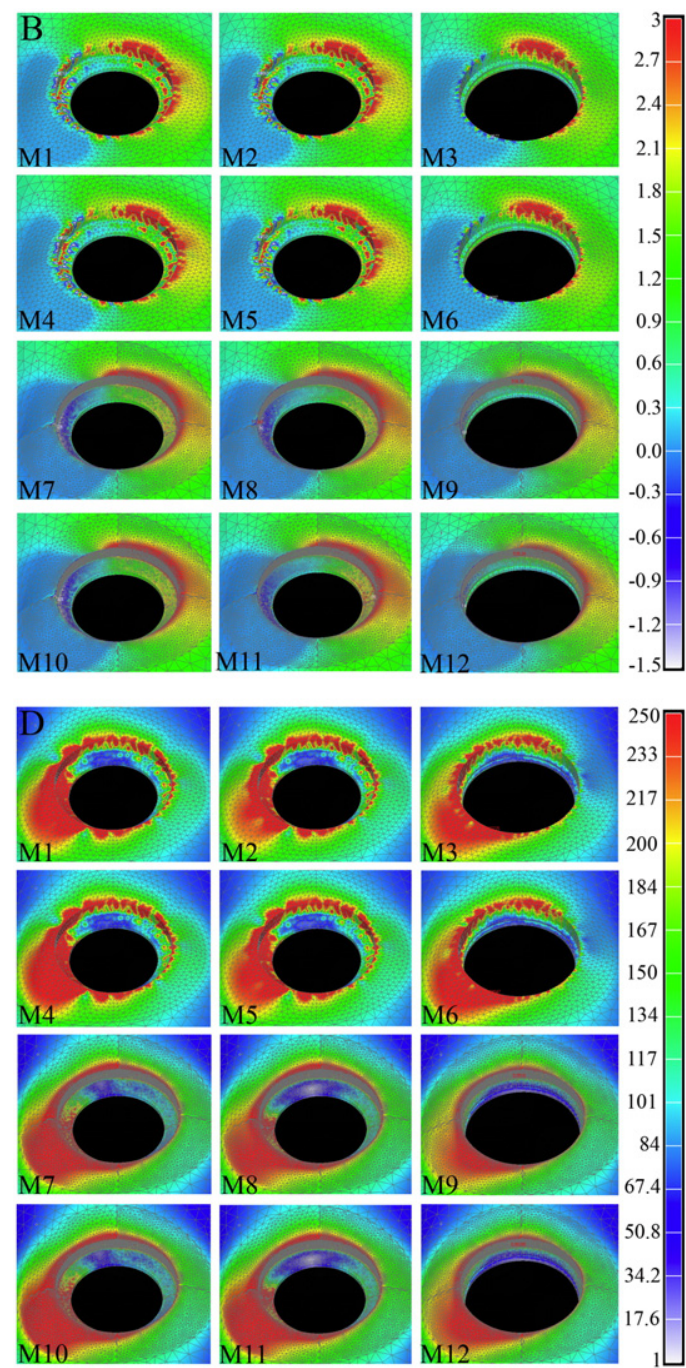

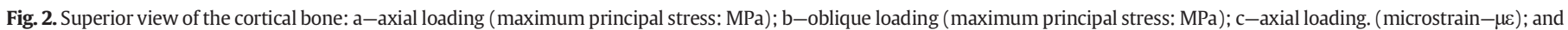
$\mathrm{d}-$ oblique loading (microstrain $-\mu \varepsilon$ ).

treated surface ( mean $=1.887 \mathrm{MPa}$ ), as can be seen in detail for each model in Table 3.

Fig. 5a and b shows maps of maximum principal stress for the different faces that were analyzed under oblique loading for the models of implants with machined (Fig. 5a) and treated surfaces (Fig. 5b) for type IV bone (models 4-6: machined surface; models 9-12: treated surface). Under oblique loading, it can be observed that the models of a treated surface increased the area of stress distribution (Fig. 5b) compared to the models of the machined surface. Moreover, the Morse taper showed the best pattern of stress distribution in both surfacetreatment situations compared to other models. This tendency was also persistent for the other models presented.

The bone-microstrain analysis showed that, under axial loading, the treated surface increased the areas and magnitude of microstrain around the implant $(p<0.001)$ for all of the models (Table 4$)$ and also increased the areas and magnitude of bone microstrain $(p<0.001)$ for the implants of a treated surface (mean $=349.196 \mu \varepsilon$ ) compared to implants of the machined surface $($ mean $=296.513 \mu \varepsilon$ ) under oblique loading.

\section{Discussion}

The hypotheses in this study proposed in relation to the analyzed dental implant designs were partially accepted because the external hexagon with platform switching and the external hexagon with a standard platform showed a pattern of stress distribution similar to the bone tissue using the maximum principal stress criterion. However, in terms of the bone-microstrain criterion, the platform-switching implants were more effective than the implants that consisted of an external hexagon with a standard platform under oblique loading. These findings agree with other studies in the literature [30-35] that evaluated the similarity [31] or relative advantage of the platform-switching concept [30,33-35] in the results of the stress distribution around an implant.

The Morse taper design exhibited the best biomechanical performance of all of the analyzed situations. Under oblique loading, this design decreased the magnitude of the maximum principal stress by approximately $35 \%$ and of microstrain by $43 \%$ compared to the external hexagon design with a standard platform.

Indeed, literature has consistently reported the effectiveness of the Morse taper design. Studies have demonstrated a better biomechanical performance of Morse taper design in comparison to an external hexagonal implant $[2,36]$. This is possibly associated with a drive-shaft force that is located closer to the center of the implant, which promotes stress distribution along the implant and decreases the micro-movement in the screws and abutments of the system [37]. Furthermore, the fact that the Morse taper exhibits a line of cementation may have favored stress and microstrain dissipations on the bone tissue, as was reported in a previous study [2]. 


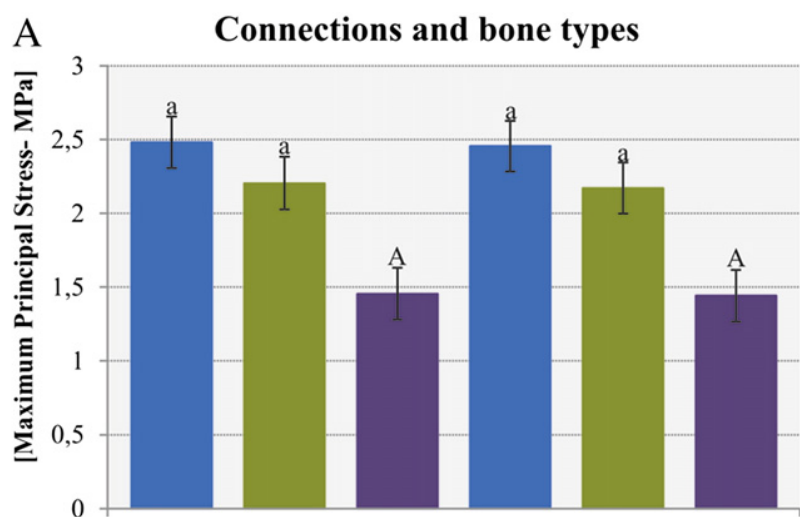

$\varpi \mathrm{EH}(\mathrm{III}) \quad \mathrm{PSW}(\mathrm{III}) \quad \mathrm{MT}(\mathrm{III}) \quad \mathrm{EH}(\mathrm{IV}) \quad \mathrm{PSW}$ (IV) $\quad \mathrm{MT}$ (IV)

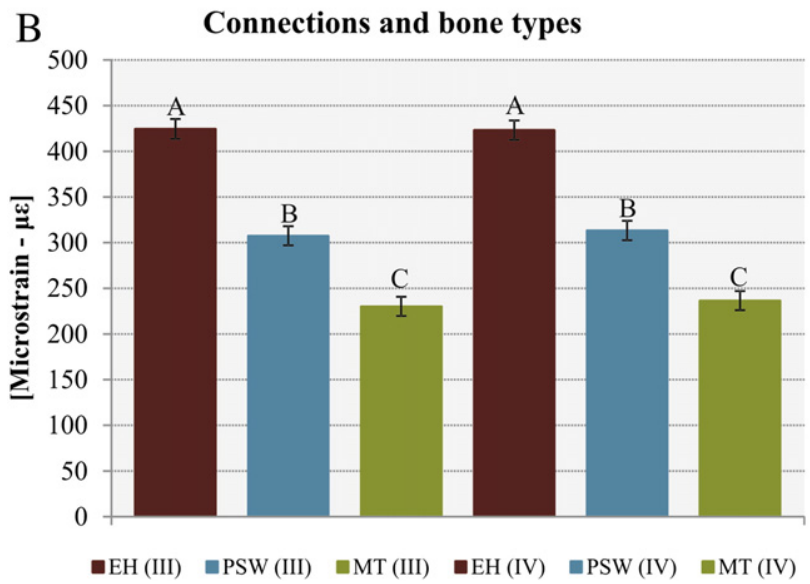

Fig. 3. a: average maximum principal stress for the different models analyzed. Uppercase/ lowercase letters $(\mathrm{A} / \mathrm{a})$ presented $\mathrm{p}<0.05$ and, similar letters lowercase $(\mathrm{a}, \mathrm{a})$ presented $\mathrm{p}>0.05$, oblique loading; $\mathrm{b}$ : analysis of bone microstrain for different models that were analyzed. Different uppercase letters (A,B; A,C; B,C) presented $\mathrm{p}<0.05$ and, similar uppercase letters $(A, A ; B, B ; C, C)$ presented $p>0.05$, oblique loading.: IE: external hexagon; PSW: Platform Switching; MT: Morse taper; III: type III bone; IV: type IV bone.

Regarding the different bone types that were analyzed, we observed that in only 1 analysis-microstrain criterion $(\mu \varepsilon)$ and axial loading-the type IV bone was statistically harmful for stress distribution in comparison to type III bone; in the other analyses, there was no significant difference. Therefore, the hypothesis was partially accepted. Through finite-element methods, other studies have indicated an increase in stress within low-density $[15,16]$ or osteoporotic bone [12] compared to bone tissue of better density. Another factor that could interfere with our result is the same cortical bone thickness between type III bone and type IV bone. Okumura et al. [13] indicated that the reduction of the cortical bone thickness increased the stress concentration. Therefore, the constant thickness could have had a protective effect that masked the effect of the lower modulus of elasticity employed for type IV bone.

In an analysis of the effect of the different dental implant designs and bone types, our results showed that, for type IV bone, the Morse taper was more effective than the external hexagon. These results are in agreement with Lin et al.'s [38] study using finite-element methods, which indicated that, in a low-density-type bone, the Morse taper design behaved more favorably than the external hexagon design.

Furthermore, other biomechanical variables have been indicated as important. Li et al. [14] using the method of finite 3D elements, indicated that implants with greater length represent an important variable for type IV bone. Concordant results were presented by Tada et al. [15], which also emphasized the use of greater-length implants in type IV bone. In this way, the use of a large-diameter $(5 \mathrm{~mm})$ and regularlength $(10 \mathrm{~mm})$ implant had acted effectively in terms of the stress distribution in both bone types that were analyzed.

The systematic-review study has indicated that the survival rate of implants placed in normal-density bone is greater than in low-density bone [1]. In our study, Young's modulus of trabecular bone tissue was modified in order to simulate low-density bone (type III: $1.3 \mathrm{GPa}$; type IV: $1.1 \mathrm{GPa}$ ) according to the literature [16]. A possible limitation of the bone tissue that was used is related to the architecture of the trabecular bone and cortical bone thickness [15]. In our study, the trabecular bone tissue was simplified in order to facilitate modeling. This may explain the stress/strain results, which did not show a significant difference in the pattern of stress distribution.

Our results showed a higher stress concentration under oblique loading. These data are in agreement with the literature, which indicates that lateral and oblique loadings are the most harmful to the implant structure and the bone tissue around the implant $[2,4,21]$. Thus, it is important that a meticulous occlusal adjustment in oral rehabilitation with implant prostheses be supported, since in oblique loading, conditions associated with other risk factors, such as bruxism, can induce the failure of dental implants [4].

Regarding the proposed surface treatment, there was a significant increase of the stress/strain concentration on the cortical bone tissue. It is understood that the transmission of stresses arising from occlusal loading occurs in the regions of the interfaces' contact with the bone/ implant; the smaller the area of bone contact, the greater the possibility of an overload in the region [16]. Therefore, the magnification of the surface area of these regions allowed a larger propagation and stress dissipation around the cortical bone. Consequently, the study's proposed hypothesis was rejected. In this context, the cortical bone tissue shows a modulus of elasticity that is 10 times greater than the trabecular bone tissue, which makes it resistant to deformation [16,39]. Thus, the increase of the area of the implant/bone contact in the cortical bone spreads a larger stress/strain in this region. Further, a reduction in bone density (type IV) showed a trend of increasing the stresses/strains (Table 4).

Surface treatment is one relevant factor for the survival of the dental implant [1], but there are few biomechanical studies about treated surfaces $[23,24,40,41]$. This study simulated a geometrical modification of the implant surface in which the surface treatment of the implants in the cortical bone was observed to increase the stress dissipation in this region. Similarly, other studies using finite-element methods indicated that the use of a treated surface increased the area of stress distribution when compared to a machined surface $[23,24,40,41]$.

It is noteworthy that a higher magnitude of maximum principal stress and microstrain in the cortical bone was observed in the models of a treated surface $(p<0.05)$, except during the condition of oblique loading of the maximum principal stress. These data are consistent with studies of finite elements, which have indicated the amplification of the magnitude of stresses in the cortical bone region [19,20,42]; however, there are reports that the increase of stress in the cortical region resulted in a reduction of the maximum stresses in the trabecular bone region $[20,43]$. Significant changes in the distribution of stresses in trabecular bone tissue were not observed in this study.

A relevant finding was noted in the condition of axial loading; our results indicated that there was an increase in the area and magnitude of stress/strain in the region around the implant. The literature has indicated satisfactory results for the biomechanical behavior, considering that, under axial loading, the increase in magnitude of stress in the cortical bone can reduce bone loss due to disuse/bone atrophy [44]. Other studies that only modified the coefficient of friction to simulate the effect of a treated surface also showed an increase of stresses in the bone crest of surface-treated implants [19,20]. However, one of the great advantages of our study was the modeling of a surface with a larger contact area, rather than just changing mechanical properties. 

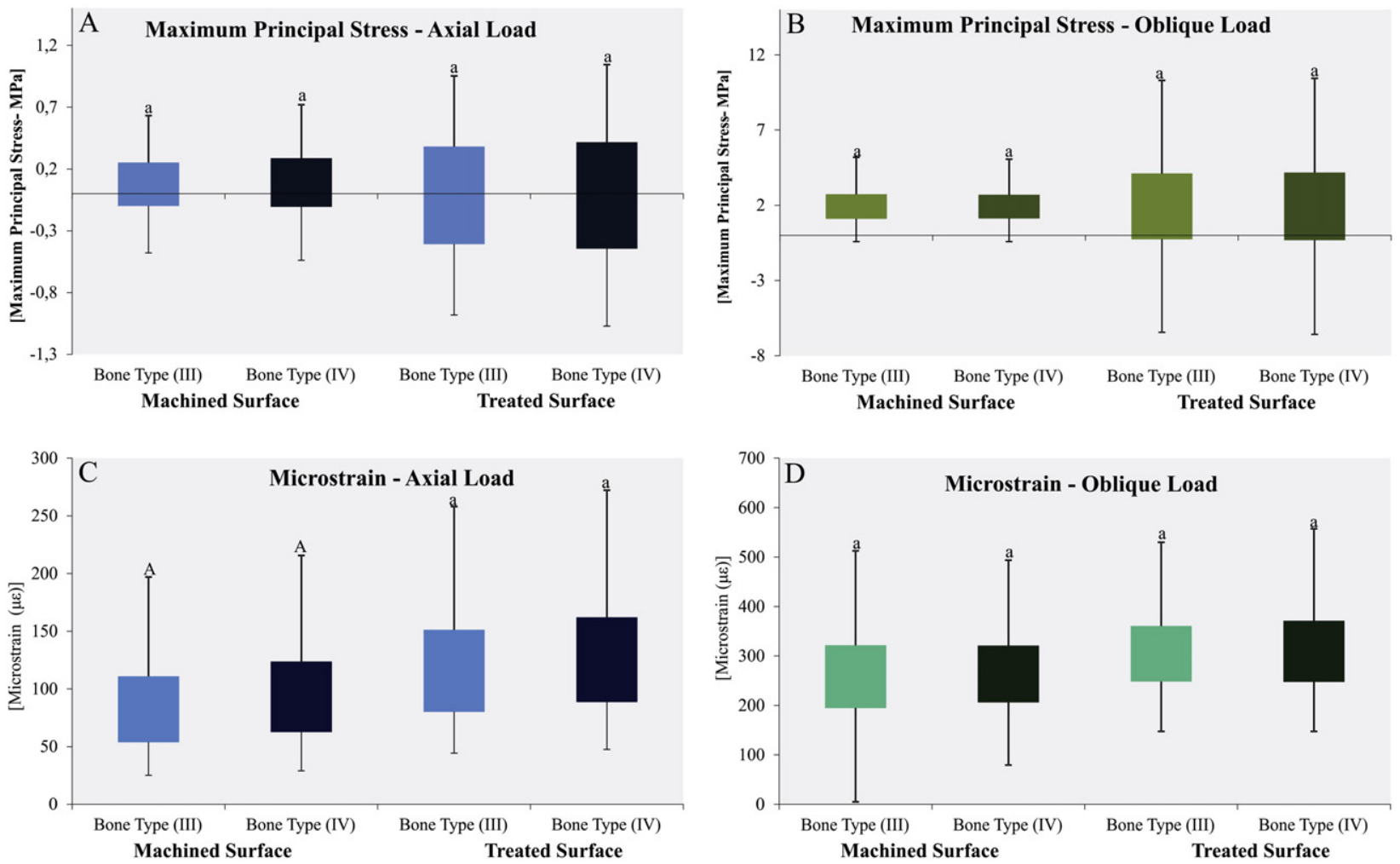

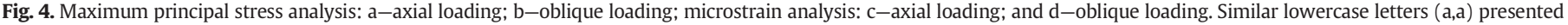
$p>0.05$, similar uppercase letters $(A, A)$ presented $p<0.05$. Type III bone and type IV bone.

Furthermore, under axial loading, it is noteworthy that the surface treatment conducted a change in the direction of load application, which predominantly emerged from traction stress to compressive stress in the region around the implant (Table 3; Fig. 2a). This fact is very beneficial, considering that the bone tissue can support a higher intensity of compressive stress when compared to tensile stresses [28].

Table 3

Maximum principal analysis in the bone tissue for different situations.

\begin{tabular}{|c|c|c|c|c|c|}
\hline Loading & Surface & Implant design & $\begin{array}{l}\text { Bone } \\
\text { type }\end{array}$ & $\begin{array}{l}\text { Mean of stress } \\
(\mathrm{MPa})\end{array}$ & $\begin{array}{l}\text { Standard } \\
\text { deviation }\end{array}$ \\
\hline \multirow[t]{12}{*}{ Axial } & \multirow[t]{6}{*}{ Machined } & \multirow[t]{2}{*}{ External hexagon } & III & 0.0589 & 0.3398 \\
\hline & & & IV & 0.0623 & 0.3734 \\
\hline & & \multirow[t]{2}{*}{ Platform switching } & III & 0.0275 & 0.2498 \\
\hline & & & IV & 0.0379 & 0.2863 \\
\hline & & \multirow[t]{2}{*}{ Morse taper } & III & -0.0210 & 0.1933 \\
\hline & & & IV & -0.0264 & 0.2219 \\
\hline & \multirow[t]{6}{*}{ Treated } & \multirow[t]{2}{*}{ External hexagon } & III & -0.273 & 0.5244 \\
\hline & & & IV & -0.292 & 0.5586 \\
\hline & & \multirow[t]{2}{*}{ Platform switching } & III & -0.176 & 0.2205 \\
\hline & & & IV & -0.173 & 0.2197 \\
\hline & & \multirow[t]{2}{*}{ Morse taper } & III & -0.239 & 0.2044 \\
\hline & & & IV & -0.272 & 0.2235 \\
\hline \multirow[t]{12}{*}{ Oblique } & \multirow[t]{6}{*}{ Machined } & \multirow[t]{2}{*}{ External hexagon } & III & 2.492 & 2.186 \\
\hline & & & IV & 2.439 & 2.137 \\
\hline & & \multirow[t]{2}{*}{ Platform switching } & III & 2.487 & 2.244 \\
\hline & & & IV & 2.522 & 2.211 \\
\hline & & \multirow[t]{2}{*}{ Morse taper } & III & 1.583 & 1.141 \\
\hline & & & IV & 1.582 & 1.162 \\
\hline & \multirow[t]{6}{*}{ Treated } & \multirow[t]{2}{*}{ External hexagon } & III & 2.472 & 4.929 \\
\hline & & & IV & 2.473 & 4.933 \\
\hline & & \multirow[t]{2}{*}{ Platform switching } & III & 1.921 & 2.199 \\
\hline & & & IV & 1.823 & 4.933 \\
\hline & & \multirow[t]{2}{*}{ Morse taper } & III & 1.330 & 1.916 \\
\hline & & & IV & 1.301 & 1.933 \\
\hline
\end{tabular}

This way, the increase of maximum principal stress and micro-strain under axial loading can be analyzed as an improvement in the physiological behavior of bone tissue [45]. Hansson [45] indicated that implants with a treated surface can increase the magnitude of stresses in the cortical bone under axial loading, and this situation can be beneficial, since the bone tissue supports threshold stress higher than the values identified in the treated surface, thus indicating that stimulation of the cortical bone under axial loading of a machined surface by compressive stresses is insufficient to preserve the bone tissue around an implant. Use of the treated implant surface will mechanically stimulate loading and stress distribution in the region. Indeed, a significant increase in the magnitude of stresses under axial loading in implants with a treated surface (mean $=0.238 \mathrm{MPa}$ ), in comparison to a machined surface (mean $=0.02 \mathrm{MPa}$ ), was observed.

Consequently, it may be a dilemma to adopt a treated surface that can promote a faster and more efficient osseointegration process in the region of the cortical bone, since it may simultaneously increase the level of stress in the cortical-bone interface; however, it is understood that the increase in the stress-controlled level can stimulate the maintenance of osseointegration [43]. In this respect, the maximum levels of stress (oblique loading, treated-surface mean of $1.887 \mathrm{MPa}$; machined-surface mean of $2.184 \mathrm{MPa}$ ) and strain (oblique loading, treated-surface mean of $349.196 \mu \varepsilon$; machined-surface mean of $296.513 \mu \varepsilon$ ) analyzed in this region of cortical bone are compatible with physiological values established in the literature of 72-76 MPa traction stress and 140-170 MPa compressive stress, [46], and, further, are compatible with values of bone microstrain acceptable for bone tissue [29]. With respect to bone microstrain, according to Frost's mechanostat theory, in order to maintain suitable conditions, bonemicrostrain values should not exceed $3000 \mu \varepsilon$ (overload) or be less than 50-100 $\mu \varepsilon$ (resorption/disuse) $[29,47]$; thus, bone-deformation values are within physiological parameters.

In contrast to this study, which changed the geometry conditions of the finite-element mesh, some studies have considered the surface 
A
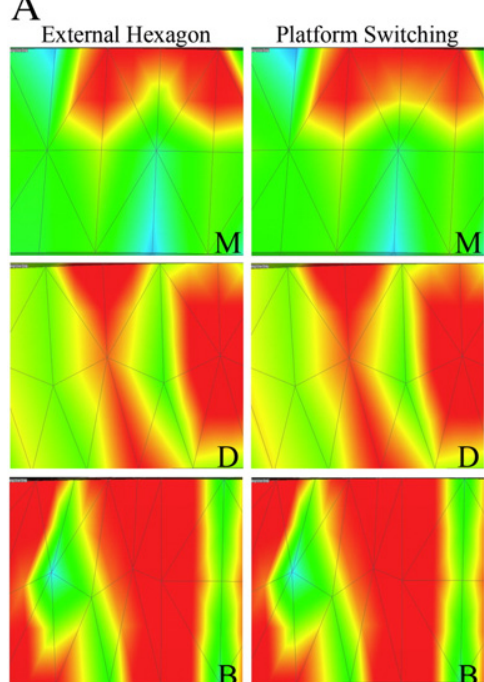

B
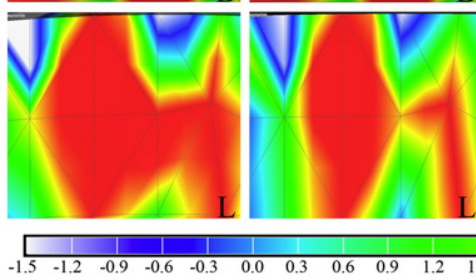

$0.3 \quad 0.6$
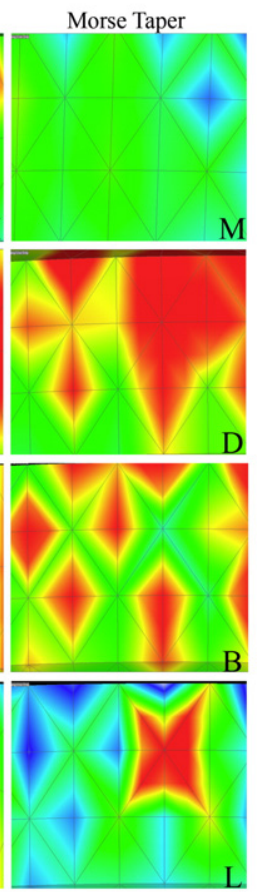

B

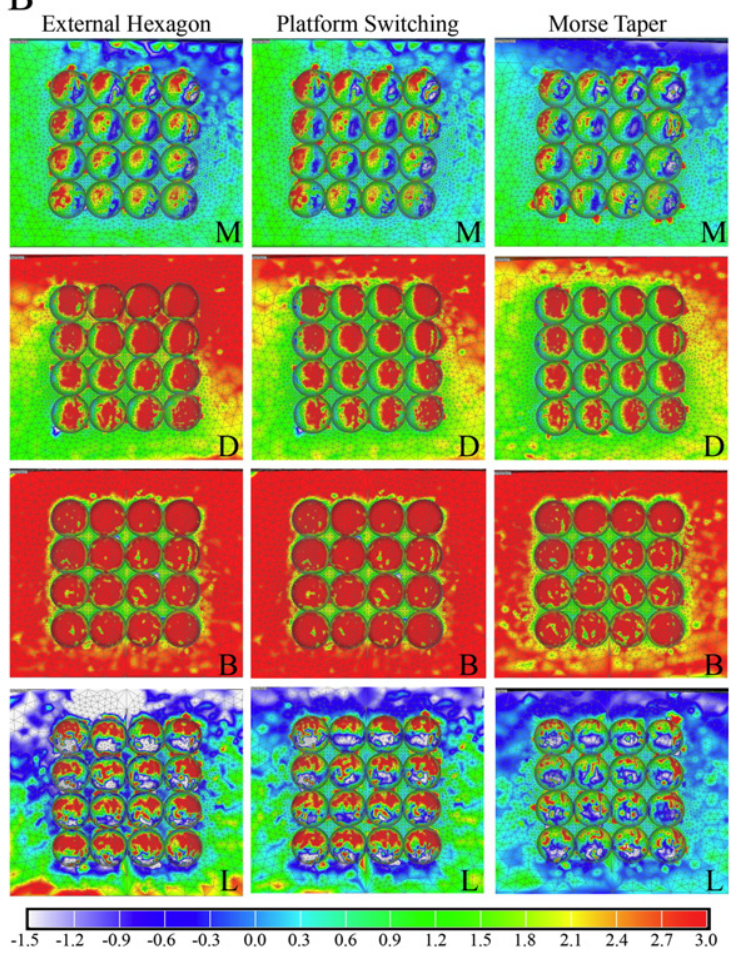

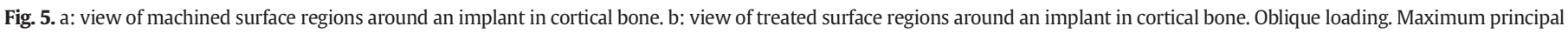
stress (MPa). M: mesial; D: distal; B: buccal; L: lingual. Type IV bone (a: M to M; b: M to MM2).

treatment by only simulating the change of the coefficient of friction within the implant/bone tissue $[19,20,43]$. Such research has shown similar results to our study (i.e., increasing the magnitude of stresses in the cortical bone). Our study showed a difference from previous studies $[19,20,43]$ because the provision of a change in the geometry of the implant allowed for an increased bone-contact surface.

Table 4

Microstrain analysis in the bone tissue for different situations.

\begin{tabular}{|c|c|c|c|c|c|}
\hline Loading & Surface & Implant design & $\begin{array}{l}\text { Bone } \\
\text { type }\end{array}$ & $\begin{array}{l}\text { Mean of } \\
\text { microstrain } \\
(\mu \varepsilon)\end{array}$ & $\begin{array}{l}\text { Standard } \\
\text { deviation }\end{array}$ \\
\hline \multirow[t]{12}{*}{ Axial } & \multirow[t]{6}{*}{ Machined } & External & III & 109.668 & 61.687 \\
\hline & & hexagon & IV & 119.369 & 69.11 \\
\hline & & Platform & III & 80.917 & 42.80 \\
\hline & & switching & IV & 95.410 & 49.78 \\
\hline & & \multirow[t]{2}{*}{ Morse taper } & III & 73.403 & 22.833 \\
\hline & & & IV & 84.551 & 26.279 \\
\hline & \multirow[t]{6}{*}{ Treated } & External & III & 179.767 & 73.478 \\
\hline & & hexagon & IV & 187.454 & 74.614 \\
\hline & & Platform & III & 105.346 & 38.809 \\
\hline & & switching & IV & 116.226 & 49.782 \\
\hline & & Morse taper & III & 101.929 & 53.428 \\
\hline & & & IV & 106.980 & 32.267 \\
\hline \multirow[t]{12}{*}{ Oblique } & \multirow[t]{6}{*}{ Machined } & External & III & 360.428 & 243.000 \\
\hline & & hexagon & IV & 366.086 & 245.150 \\
\hline & & Platform & III & 312.501 & 163.009 \\
\hline & & switching & IV & 318.375 & 164.371 \\
\hline & & Morse taper & III & 205.699 & 82.054 \\
\hline & & & IV & 215.989 & 84.620 \\
\hline & \multirow[t]{6}{*}{ Treated } & External & III & 488.303 & 256.594 \\
\hline & & hexagon & IV & 480.205 & 262.568 \\
\hline & & Platform & III & 302.590 & 61.766 \\
\hline & & switching & IV & 308.201 & 64.928 \\
\hline & & Morse taper & III & 254.550 & 48.580 \\
\hline & & & IV & 261.327 & 52.526 \\
\hline
\end{tabular}

The surface modification of implants is recommended because it enlarges the area of bone contact [1], thus allowing better resistance to shear forces due to the increased friction coefficient [19]. However, the literature suggests that an increase of stresses in the cortical bone, with the increase of the surface roughness in this region [20], must be properly evaluated in order to prevent bone loss around the implant.

The main limitations of the study are related to the constraints of a computer simulation $[2,21]$. Our study considered linearly elastic, isotropic, and homogeneous material properties. Future studies should use the concept of non-linear analysis and an anisotropic bone. However, within the conditions of the study, the finite-element method shows advantages because it allows an analysis of the internal structures of bone tissue and implant-supported prostheses. It presents an advantage when compared with other methodologies, but clinical studies must evaluate the benefits of the biomechanical variables that are analyzed in this study.

Finally, the results indicate the superiority of the Morse taper design in stress distribution and implants, as the concept of a switching platform did not reveal biomechanical disadvantages in comparison to an external hexagon with a standard platform. Therefore, biologically, the conditions of better bone preservation around the implant with the use of a Morse taper design and platform switching endorse the use of these systems [7,36] in comparison to an external hexagon with a standard platform [7].

Furthermore, increasing the surface area of the implants with the treated surface did not harm the stress distribution to nonphysiological levels. Therefore, clinical [48] and review studies [1,49] endorse the benefits of a treated surface, mainly for low-density bone (type IV); thus, we believe in the biomechanical viability of these treated surfaces in comparison to machined surfaces. Randomized controlled trials must consider the longevity outcome of peri-implant bone loss, the survival of implants with surface treatment, and different types of connections, as well as possible complications of implant-supported prostheses, especially in terms of fixation screws. 


\section{Conclusion}

Based on the methodology used and the results obtained, the following can be concluded:

- The Morse taper design showed better biomechanical behavior independent of the type of analysis.

- An external hexagon with platform switching was more favorable than an external hexagon with a standard platform.

- The different bone types that were analyzed indeed indicated a significant difference in the distribution of stresses/strains.

- Surface treatment increased the area of stress/strain concentration on the cortical bone.

- Oblique loading was more harmful to the stress distribution than axial loading.

\section{Acknowledgments}

- The authors would like to express gratitude to the State of Sao Paulo Research Foundation (FAPESP) for the scholarship (2010/15734-1) provided.

- Renato Archer Research Center, Campinas, SP, Brazil.

- Conexao Sistemas de Prótese, Arujá, São Paulo, Brazil.

\section{References}

[1] M.C. Goiato, D.M. Dos Santos, J.F. Jr Santiago, A. Moreno, E.P. Pellizzer, Longevity of dental implants in type IV bone: a systematic review, Int. J. Oral Maxillofac. Surg. 43 (2014) 1108-1116.

[2] D.A. de Faria Almeida, E.P. Pellizzer, F.R. Verri, J.F. Santiago Jr., P.S. de Carvalho, Influence of tapered and external hexagon connections on bone stresses around tilted dental implants: three-dimensional finite element method with statistical analysis, J. Periodontol. 85 (2014) 261-269.

[3] E.P. Pellizzer, R.I. Carli, R.M. Falcon-Antenucci, F.R. Verri, M.C. Goiato, L.M. Villa Photoelastic analysis of stress distribution with different implant systems, J. Ora Implantol. 40 (2014) 117-122.

[4] F.R. Verri, V.E. Batista, J.F. Santiago Jr., D.A. Almeida, E.P. Pellizzer, Effect of crown-toimplant ratio on peri-implant stress: a finite element analysis, Mater. Sci. Eng. C Mater. Biol. Appl. 45 (2014) 234-240.

[5] L.P. Faverani, V.A. Barao, G. Ramalho-Ferreira, J.A. Delben, M.B. Ferreira, I.R. Garcia Junior, et al., The influence of bone quality on the biomechanical behavior of fullarch implant-supported fixed prostheses, Mater. Sci. Eng. C Mater. Biol. Appl. 37 (2014) 164-170

[6] R. Skalak, Biomechanical considerations in osseointegrated prostheses, J. Prosthet Dent. 49 (1983) 843-848

[7] J.F.J. Santiago, V.E. de Souza Batista, F.R. Verri, H.M. Honorio, C.C. de Mello, D.A Almeida, et al., Platform-switching implants and bone preservation: a systematic review and meta-analysis, Int. J. Oral Maxillofac. Surg. (2015).

[8] R. Adell, U. Lekholm, B. Rockler, P.I. Branemark, A 15-year study of osseointegrated implants in the treatment of the edentulous jaw, Int. J. Oral Surg. 10 (1981) 387-416.

[9] M.A. Atieh, H.M. Ibrahim, A.H. Atieh, Platform switching for marginal bone preservation around dental implants: a systematic review and meta-analysis, J. Periodontol. 81 (2010) 1350-1366.

[10] S. Annibali, I. Bignozzi, M.P. Cristalli, F. Graziani, G. La Monaca, A. Polimeni, Peri-implant marginal bone level: a systematic review and meta-analysis of studies comparing platform switching versus conventionally restored implants, J. Clin. Periodontol. 39 (2012) 1097-1113.

[11] R.J. Lazzara, S.S. Porter, Platform switching: a new concept in implant dentistry for controlling postrestorative crestal bone levels, Int. J. Periodontics Restorative Dent 26 (2006) 9-17.

[12] J.R. Xiao, Y.F. Li, S.M. Guan, L. Song, L.X. Xu, L. Kong, The biomechanical analysis of simulating implants in function under osteoporotic jawbone by comparing cylindrical, apical tapered, neck tapered, and expandable type implants: a 3-dimensional finite element analysis, J. Oral Maxillofac. Surg. 69 (2011) e273-e281.

[13] N. Okumura, R. Stegaroiu, E. Kitamura, K. Kurokawa, S. Nomura, Influence of maxillary cortical bone thickness, implant design and implant diameter on stress around implants: a three-dimensional finite element analysis, J. Prosthodont Res. 54 (2010) 133-142.

[14] T. Li, L. Kong, Y. Wang, K. Hu, L. Song, B. Liu, et al., Selection of optimal dental implant diameter and length in type IV bone: a three-dimensional finite element analysis, Int. J. Oral Maxillofac. Surg. 38 (2009) 1077-1083.

[15] S. Tada, R. Stegaroiu, E. Kitamura, O. Miyakawa, H. Kusakari, Influence of implant design and bone quality on stress/strain distribution in bone around implants: a 3-dimensional finite element analysis, Int. J. Oral Maxillofac. Implants 18 (2003) 357-368.
[16] M. Sevimay, F. Turhan, M.A. Kilicarslan, G. Eskitascioglu, Three-dimensional finite element analysis of the effect of different bone quality on stress distribution in an implant-supported crown, J. Prosthet. Dent. 93 (2005) 227-234.

[17] M.I. Muelas-Jimenez, M.V. Olmedo-Gaya, F.J. Manzano-Moreno, C. Reyes-Botella, M. Vallecillo-Capilla, Long-term survival of dental implants with different prosthetic loading times in healthy patients: a 5-year retrospective clinical study, J. Prosthodont. (2015).

[18] D.L. Cochran, J.M. Jackson, J.P. Bernard, C.M. ten Bruggenkate, D. Buser, T.D. Taylor, et al., A 5-year prospective multicenter study of early loaded titanium implants with a sandblasted and acid-etched surface, Int. J. Oral Maxillofac. Implants 26 (2011) 1324-1332.

[19] H.L. Huang, J.T. Hsu, L.J. Fuh, M.G. Tu, C.C. Ko, Y.W. Shen, Bone stress and interfacial sliding analysis of implant designs on an immediately loaded maxillary implant: a non-linear finite element study, J. Dent. 36 (2008) 409-417.

[20] H.L. Huang, J.T. Hsu, L.J. Fuh, D.J. Lin, M.Y. Chen, Biomechanical simulation of various surface roughnesses and geometric designs on an immediately loaded dental implant, Comput. Biol. Med. 40 (2010) 525-532.

[21] J.F. Santiago Junior, E.P. Pellizzer, F.R. Verri, P.S. de Carvalho, Stress analysis in bone tissue around single implants with different diameters and veneering materials: a 3-D finite element study, Mater. Sci. Eng. C Mater. Biol. Appl. 33 (2013) 4700-4714.

[22] R.M. Falcon-Antenucci, E.P. Pellizzer, P.S. de Carvalho, M.C. Goiato, P.Y. Noritomi, Influence of cusp inclination on stress distribution in implant-supported prostheses. A three-dimensional finite element analysis, J. Prosthodont. 19 (2010) 381-386.

[23] R.M. Pilliar, G. Sagals, S.A. Meguid, R. Oyonarte, D.A. Deporter, Threaded versus porous-surfaced implants as anchorage units for orthodontic treatment: threedimensional finite element analysis of peri-implant bone tissue stresses, Int. J. Oral Maxillofac. Implants 21 (2006) 879-889.

[24] R.C. Savadi, J. Agarwal, R.S. Agarwal, V. Rangarajan, Influence of implant surface topography and loading condition on stress distribution in bone around implants: a comparative 3D FEA, J. Indian Prosthodont Soc. 11 (2011) 221-231.

[25] A. Sertgoz, Finite element analysis study of the effect of superstructure material on stress distribution in an implant-supported fixed prosthesis, Int. J. Prosthodont. 10 (1997) 19-27.

[26] U.R. Benzing, H. Gall, H. Weber, Biomechanical aspects of two different implantprosthetic concepts for edentulous maxillae, Int. J. Oral Maxillofac. Implants 10 (1995) 188-198.

[27] K.J. Anusavice, B. Hojjatie, Stress distribution in metal-ceramic crowns with a facial porcelain margin, J. Dent. Res. 66 (1987) 1493-1498.

[28] L. Baggi, I. Cappelloni, M. Di Girolamo, F. Maceri, G. Vairo, The influence of implant diameter and length on stress distribution of osseointegrated implants related to crestal bone geometry: a three-dimensional finite element analysis, J. Prosthet. Dent. 100 (2008) 422-431.

[29] M.B. dos Santos, A. Bacchi, L. Correr-Sobrinho, R.L. Consani, The influence of clip material and cross sections of the bar framework associated with vertical misfit on stress distribution in implant-retained overdentures, Int. J. Prosthodont. 27 (2014) 26-32.

[30] E.P. Pellizzer, R.M. Falcon-Antenucci, P.S. de Carvalho, J.F. Santiago, S.L. de Moraes, B.M. de Carvalho, Photoelastic analysis of the influence of platform switching on stress distribution in implants, J. Oral. Implantol. 36 (2010) 419-424.

[31] E.P. Pellizzer, F.R. Verri, R.M. Falcon-Antenucci, J.F. Junior, P.S. de Carvalho, S.L. de Moraes, et al., Stress analysis in platform-switching implants: a 3-dimensional finite element study, J. Oral Implantol. 38 (2012) 587-594.

[32] J.T. Hsu, L.J. Fuh, D.J. Lin, Y.W. Shen, H.L. Huang, Bone strain and interfacial sliding analyses of platform switching and implant diameter on an immediately loaded implant: experimental and three-dimensional finite element analyses, J. Periodontol. 80 (2009) 1125-1132.

[33] C.L. Chang, C.S. Chen, M.L. Hsu, Biomechanical effect of platform switching in implant dentistry: a three-dimensional finite element analysis, Int. J. Oral Maxillofac. Implants 25 (2010) 295-304.

[34] Y. Maeda, J. Miura, I. Taki, M. Sogo, Biomechanical analysis on platform switching: is there any biomechanical rationale? Clin. Oral Implants Res. 18 (2007) 581-584.

[35] P. Khurana, A. Sharma, K.K. Sodhi, Influence of fine threads and platform-switching on crestal bone stress around implant-a three-dimensional finite element analysis, J. Oral Implantol. 39 (2013) 697-703.

[36] M.C. Goiato, E.P. Pellizzer, E.V. da Silva, R. Bonatto Lda, D.M. Dos Santos, Is the internal connection more efficient than external connection in mechanical, biological, and esthetical point of views? A systematic review, Oral Maxillofac. Surg. 19 (2015) 229-242

[37] P.P. Binon, Implants and components: entering the new millennium, Int. J. Oral Maxillofac. Implants 15 (2000) 76-94

[38] C.L. Lin, J.C. Wang, L.C. Ramp, P.R. Liu, Biomechanical response of implant systems placed in the maxillary posterior region under various conditions of angulation, bone density, and loading, Int. J. Oral Maxillofac. Implants 23 (2008) 57-64.

[39] X. Rodriguez-Ciurana, X. Vela-Nebot, M. Segala-Torres, C. Rodado-Alonso, V. Mendez-Blanco, M. Mata-Bugueroles, Biomechanical repercussions of bone resorption related to biologic width: a finite element analysis of three implant-abutment configurations, Int. J. Periodontics Restorative Dent. 29 (2009) 479-487.

[40] H.Y. Cheng, K.T. Chu, F.C. Shen, Y.N. Pan, H.H. Chou, K.L. Ou, Stress effect on bone remodeling and osseointegration on dental implant with novel nano/microporous surface functionalization, J. Biomed. Mater. Res. A 101 (2013) 1158-1164.

[41] H. Alexander, J.L. Ricci, G.J. Hrico, Mechanical basis for bone retention around dental implants, J. Biomed. Mater. Res. B Appl. Biomater. 88 (2009) 306-311.

[42] F. Lofaj, J. Kucera, D. Nemeth, L. Kvetkova, Finite element analysis of stress distributions in mono- and bi-cortical dental implants, Mater. Sci. Eng. C Mater. Biol. Appl. 50 (2015) 85-96. 
[43] B. Bahrami, S. Shahrbaf, B. Mirzakouchaki, F. Ghalichi, M. Ashtiani, N. Martin, Effect of surface treatment on stress distribution in immediately loaded dental implants-a 3D finite element analysis, Dent. Mater. 30 (2014) e89-e97.

[44] H. Vaillancourt, R.M. Pilliar, D. McCammond, Factors affecting crestal bone loss with dental implants partially covered with a porous coating: a finite element analysis, Int. J. Oral Maxillofac. Implants 11 (1996) 351-359.

[45] S. Hansson, The implant neck: smooth or provided with retention elements. A biomechanical approach, Clin. Oral Implants Res. 10 (1999) 394-405.

[46] G. Papavasiliou, P. Kamposiora, S.C. Bayne, D.A. Felton, Three-dimensional finite element analysis of stress-distribution around single tooth implants as a function of bony support, prosthesis type, and loading during function, J. Prosthet. Dent. 76 (1996) 633-640.
[47] H.M. Frost, Bone's mechanostat: a 2003 update, Anat. Rec. A: Discov. Mol. Cell. Evol. Biol. 275 (2003) 1081-1101.

[48] J. Ganeles, A. Zollner, J. Jackowski, C. ten Bruggenkate, J. Beagle, F. Guerra, Immediate and early loading of Straumann implants with a chemically modified surface (SLActive) in the posterior mandible and maxilla: 1-year results from a prospective multicenter study, Clin. Oral Implants Res. 19 (2008) 1119-1128.

[49] R.M. Stach, S.S. Kohles, A meta-analysis examining the clinical survivability of machined-surfaced and osseotite implants in poor-quality bone, Implant. Dent. 12 (2003) 87-96. 